\title{
Thunderclap headache and boomerang sign in dengue encephalopathy
}

\author{
Amit Shankar Singh ${ }^{1}$, Jeenendra Prakash Singhvi ${ }^{2}$, Harpreet Singh Mann ${ }^{1}$, Arshdeep Singh Sidhu ${ }^{\mathbf{3}}$ \\ From ${ }^{1}$ Consultant, ${ }^{2}$ Senior Consultant, Department of Neurology, ${ }^{3}$ DNB Medicine Resident, Department of Medicine, Fortis Hospital, \\ Mohali, Punjab, India
}

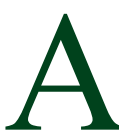

n 18-year-old boy presented with high-grade fever with rashes over the body for 2-3 days followed by abrupt

onset, severe holocranial headache associated with photophobia, phonophobia, nausea, and vomiting. Headache was so severe and sudden that the patient was immediately rushed to the emergency. The patient also developed slurring of speech and drowsiness later that day. On examination, the patient was febrile with a temperature of $101 \mathrm{~F}$, his blood pressure was $100 / 60 \mathrm{mmHg}$, pulse rate was $110 / \mathrm{min}$, and respiratory rate was $24 / \mathrm{min}$. The patient was irritable, with irrelevant talking and restlessness. Cranial nerve, motor, sensory, and cerebellar examination were normal. His headache subsided with intravenous analgesics but fever and rashes persisted. Speech and sensorium improved along with headache. On investigation, his platelet counts were low $(24,000 / \mu \mathrm{L})$ and pyrexia workup showed dengue NS1 antigen positive. Brain magnetic resonance imaging (MRI) showed diffusion restriction in diffusion-weighted imaging images in the splenium of corpus callosum (Fig. 1a and b). Magnetic resonance angiography and venography were normal and no contrast enhancement was seen. The rest of the investigations were normal. The patient's fever, rashes, and platelet counts improved over a few days, and a repeat brain MRI after 2 weeks showed no diffusion restriction (Fig. 2a and b).

Transient splenium hyperintensity in MRI is called as Boomerang sign due to its resemblance with boomerang [1]. It can be seen in infective encephalitis/encephalopathy, post-ictal state, anti-epileptic drugs withdrawal, toxic or metabolic encephalopathy, and occasionally in few primary headaches such as migraine and hemicrania continua [2-4]. In this case, probably dengue encephalopathy associated with capillary leakage caused neuronal damage in the splenium of the corpus callosum and hence may have triggered the cortical spreading depression causing headache [5].

\section{Access this article online}

Received - 21 September 2021

Initial Review - 07 October 2021

Accepted - 12 October 2021

DOI: $10.32677 /$ ijcr.v7i10.3096

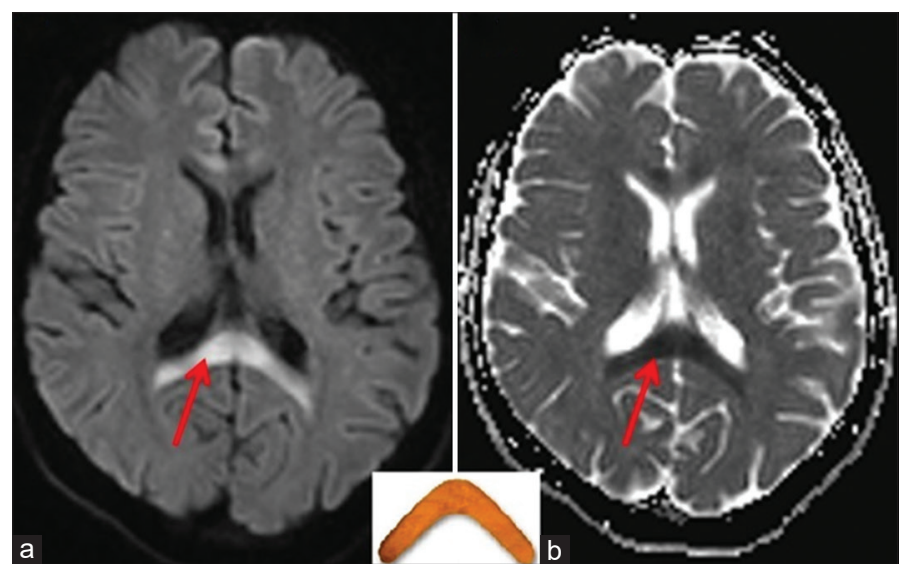

Figure 1: Diffusion-weighted imaging and apparent diffusion coefficient images showing diffusion restriction in splenium of corpus callosum (red arrows) at presentation (a and b). Inset image showing wooden boomerang, resembling restricted area in splenium of this patient
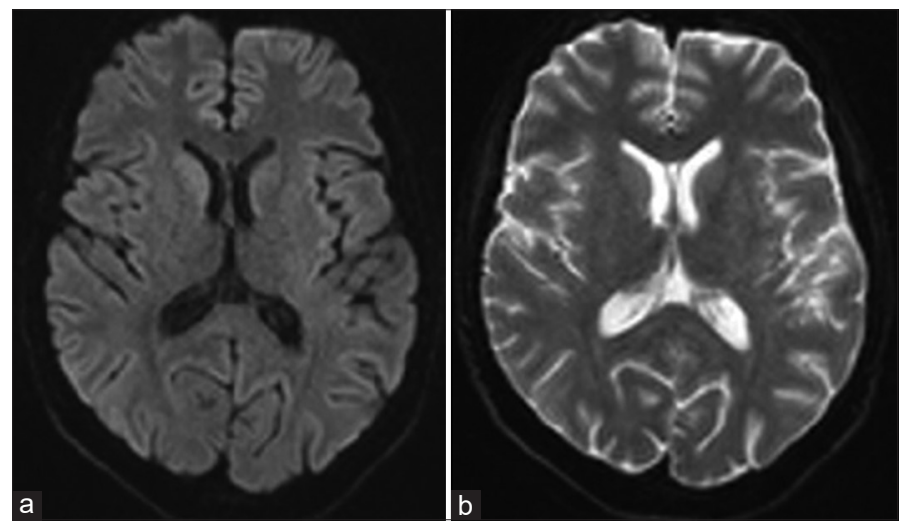

Figure 2: Diffusion-weighted imaging and apparent diffusion coefficient images showing disappearance of diffusion restriction from splenium of corpus callosum after 2 weeks ( $a$ and $b$ )

\section{ACKNOWLEDGMENT}

Dr. Debashish Chowdhary, Head of Department, In-charge Headache Clinic, Department of Neurology, GB Pant Hospital, New Delhi.

Correspondence to: Dr Amit Shankar Singh, Consultant Neurologist, Department of Neurology, Fortis Hospital, Mohali, Punjab, India. E-mail: amitkgmu@gmail.com

(C) 2021 Creative Commons Attribution-NonCommercial 4.0 International License (CC BY-NC-ND 4.0). 


\section{REFERENCES}

1. Malhotra HS, Garg RK, Vidhate MR, Sharma PK. Boomerang sign: Clinical significance of transient lesion in splenium of corpus callosum. Ann Indian Acad Neurol 2012;15:151.

2. Schick D, Robbins MS. Images from headache: Acute headache with a reversible splenium lesion. Headache 2015;55:427-9.

3. Agarwal A, Kanupriya V, Maller V. Transient restricted diffusion in the splenium of the corpus callosum in migraine with aura. Wien Klin Wochenschr 2012;124:146-7.

4. Samanta D. Transient lesion in the splenium of the corpus callosum in status migrainosus. Acta Neurol Belg 2015;115:397-8.

5. Lin FY, Yang CY. Reversible splenial lesion of the corpus callosum in migraine with aura. Neurologist 2011;17:157-9.

Funding: Nil; Conflicts of interest: Nil.

How to cite this article: Singh AS, Singhvi JP, Mann HS, Sidhu AS. Thunderclap headache and Boomerang sign in Dengue encephalopathy. Indian J Case Reports. 2021;7(10):467-468. 